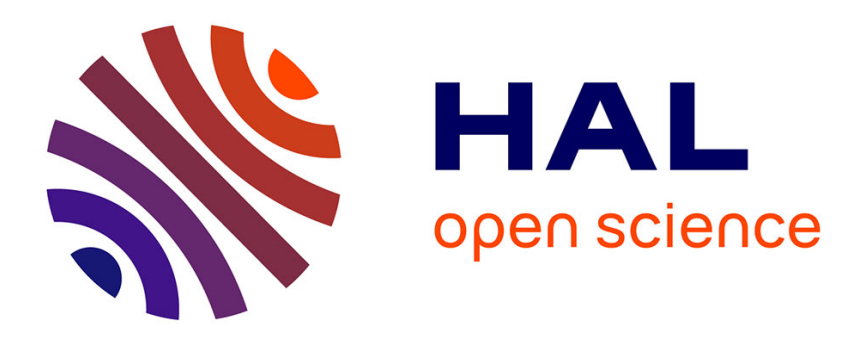

\title{
Recent developments in sub-Doppler spectroscopy in a thin cell
}

\author{
Stéphan Briaudeau, S. Saltiel, J.R.R. Leite, M. Oria, A. Bramati, A. Weis, D
} Bloch, M. Ducloy

\section{- To cite this version:}

Stéphan Briaudeau, S. Saltiel, J.R.R. Leite, M. Oria, A. Bramati, et al.. Recent developments in sub-Doppler spectroscopy in a thin cell. Journal de Physique IV Proceedings, 2000, pp.8 - 145. 10.1051/jp4:2000831 . hal-01514717

\section{HAL Id: hal-01514717 https://hal.science/hal-01514717}

Submitted on 26 Apr 2017

HAL is a multi-disciplinary open access archive for the deposit and dissemination of scientific research documents, whether they are published or not. The documents may come from teaching and research institutions in France or abroad, or from public or private research centers.
L'archive ouverte pluridisciplinaire HAL, est destinée au dépôt et à la diffusion de documents scientifiques de niveau recherche, publiés ou non, émanant des établissements d'enseignement et de recherche français ou étrangers, des laboratoires publics ou privés. 


\title{
RECENT DEVELOPMENTS IN SUB-DOPPLER SPECTROSCOPY IN A THIN CELL
}

content published as J. Phys IV France (2000) Pr 8-145

\author{
S. BRIAUDEAU ${ }^{1}$, S. SALTIEL ${ }^{2}$, J.R.R. LEITE ${ }^{3}$, M. ORIA ${ }^{4}$, \\ A. BRAMATI ${ }^{5}$, A. WEIS ${ }^{6}$, D. BLOCH and M. DUCLOY \\ Laboratoire de Physique des Lasers, UMR 7538 du CNRS \\ Université Paris-Nord 93430 Villetaneuse
}

\begin{abstract}
We report on the special sub-Doppler features of high-resolution spectroscopy in a thin cell, in conditions when the atomic free path is anisotropic as due to the special cell geometry. The most recent developments include linear spectroscopy under normal incidence, an extension to transition between excited states, and the observation of atoms flying under grazing incidence in a pump-probe scheme with spatially separated beams
\end{abstract}

\section{INTRODUCTION}

For a dilute gas, the special geometry of the container can affect the spectral lineshapes, notably when the transient effects, that are velocity-dependent, have to be included in the analysis. It was early shown by Dicke [1] that a lineshape narrowing could be observed, in the microwave domain, as a result of the relatively enhanced contribution of the slow atoms. In the optical domain, we had recently observed subDoppler features in the transmission, under normal incidence, of a single resonant beam through an alkali vapor cell whose thickness is $10-1000 \mu m$ [2]. In these experiments, performed on the $\mathrm{D}_{2}$ line of Cs, the absorption was reduced at line center, as due to an hyperfine optical pumping transfer efficient only for those rare atoms [3] flying nearly parallel to the wall, that are insensitive to the Doppler shift, while experiencing a long interaction time. We report here on the last spectroscopic developments with thin cells.

\section{LINEAR REGIME AND COHERENT INTERACTION}

Although the hyperfine pumping of alkali metal vapors is an elementary observation in laser spectroscopy, it is nevertheless a nonlinear process : when the light power is low enough, its buildup time can largely exceed the interaction time, even for the slowest atoms. In the linear regime, the optical absorption exhibits a relatively fast transient build-up, as it is simply related to the atomic coherence, and it is susceptible to lead to an interferometric dependence with the cell length [4]. In a real cell, this partial interferometric dependence is actually washed out. Moreover, thanks to the enhanced sensitivity of a FM technique, we succeeded in observing sub-Doppler features in the transmission through a thin cell (up to $50 \mu \mathrm{m}$ thickness) under an ultra-low power irradiation $\left(1-100 \mathrm{nW} / \mathrm{cm}^{2}\right)$, ensuring a linear behavior.

\section{TRANSITION BETWEEN EXCITED STATES}

The above-demonstrated rare combination of sub-Doppler features and linear behavior, reminiscent of atomic beam spectroscopy, may offer various advantages, notably when saturation of the transition turns to be difficult or ineffective, or for transitions between excited states when a fine tuning of the intermediate

\footnotetext{
${ }^{1}$ Now at CNAM-INM (Paris)

${ }^{2}$ Permanent address : Sofia University, Bulgaria

${ }^{3}$ Universidade Federale de Pernambuco, Recife, Brazil

${ }^{4}$ Universidade Federale de Paraiba, Joao Pessoa, Brazil

${ }^{5}$ Now at University of Come, Italy

${ }^{6}$ University of Bonn, Germany
} 
steps of excitation is unwanted. In order to test such a possibility, we have investigated on the $6 \mathrm{P}_{1 / 2}-6 \mathrm{D}_{3 / 2}$ transition of Cs $(876 \mathrm{~nm})$ the transmission of thin vapor cells irradiated by a broadband pumping on the $\mathrm{D}_{1}$ line $(894 \mathrm{~nm})$. As shown on the spectrum of fig .1, a sub-Doppler signal appears centered on the atoms with null (longitudinal) velocity, superimposed to the Doppler-broadened absorption. Note that the recording is here obtained in a linear regime (optical pumping efficiency is indeed limited by the short lifetime of the excited states). More specifically, the analysis of the present sub-Doppler signal shows that it may actually originate in a (transit-time) velocity-selective pumping into the $6 \mathrm{P}_{1 / 2}$ level (which is particularly efficient on the $\mathrm{D}_{1}$ line), rather than in the coherent linear excitation at $876 \mathrm{~nm}$

\section{SATURATION SPECTROSCOPY IN SEPARATED FIELDS}

Usual saturated absorption spectroscopy with counterpropagating beams, and its specific features in the context of a thin cell, were already analyzed [3]. Here, we consider the situation (fig.2) when a spatial separation between the pump and the probe beams restricts the signal contribution to those atoms having traveled under grazing incidence. An interesting point is that the experimental set-up itself imposes the accuracy of the "grazing incidence", simply given by T/D , with $\mathrm{T}$ the cell thickness and $\mathrm{D}$ the distance between the pump and probe beam axes (assumed to be normal to the cell). This should provide an easy access to the tail of the atomic velocity distribution (i.e. those atoms with arbitrary small normal velocity, that are generally out-of-reach with the common detection techniques used for desorption measurement). Also, it eliminates the statistical difficulties related with velocity selection through low-power optical pumping in a thin cell (see discussion in [3]). In very preliminary experiments on a $20 \mu \mathrm{m}$ cell, we could observe on the $C s \mathrm{D}_{2}$ line the response of atoms pumped in a central spot (diameter $1 \mathrm{~mm}$ ), and probed by a ring shape beam (as generated by diffractive optics) 4mm away from the pump. This corresponds to an effective $2 \mathrm{~m} / \mathrm{s}$ velocity selection, already sharper than the $5 \mathrm{~m} / \mathrm{s}$ currently obtained on the $\mathrm{D}_{2}$ line.

This work was partially supported by the French-Brazilian project CAPES/COFECUB 260/98

[1] R. H. Romer and R. H. Dicke, Phys. Rev. 99, 532 (1955)

[2] S. Briaudeau et al , Europhys. Lett. 35, 337-342 (1996)

[3] S. Briaudeau et al., Phys. Rev. A 59, 3723-3735 (1999)

[4] S. Briaudeau et al., Phys. Rev. A 57 R3169-R3172 (1998).

a)

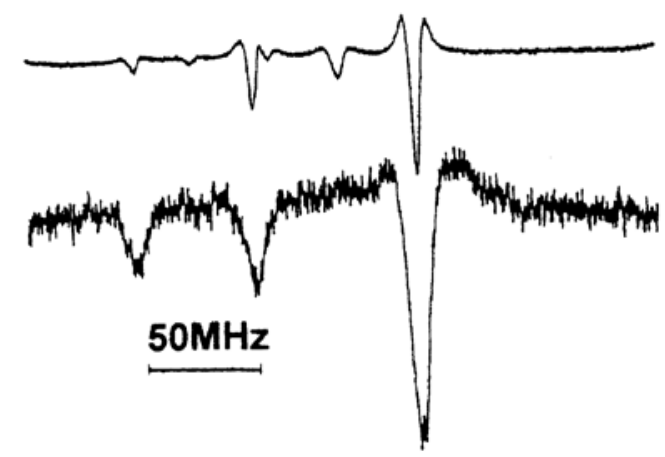

Figure 1 : Comparison between : (a) a saturated absorption spectrum on a transition between excited states (Cs $876 \mathrm{~nm}$, $6 \mathrm{P}_{1 / 2}-6 \mathrm{D}_{3 / 2}$ ) showing the Doppler-free resonance and the associated crossover resonances ; and : (b) linear absorption spectrum in a $10 \mu \mathrm{m}$ cell irradiated with a single low-power beam (here $10 \mu \mathrm{W}$, results are linear in the $50 \mathrm{nW}-100 \mu \mathrm{W}$ range). The Doppler-free peaks are associated with a velocity selection of the slowest atoms. In both experiments, the the $894 \mathrm{~nm}\left(6 \mathrm{~S}_{1 / 2}-6 \mathrm{P}_{3 / 2}\right)$ pump beam is broadband, and does not carry velocity selective. An FM modulation is applied to the probe beam, and the signal is recorded after demodulation at twice this frequency.

Figure 2 : Principle scheme of the experiment with spatially separated pump and probe beams. 